3 Livingston, S., Bridge, E. M., and Kajdi, L., Fournal of Pediatrics, 1947, 31, 509.

4 Livingston, S., The Diagnosis and Treatment of Convulsive Disorders in Children. Springfield, Charles Thomas, 1954.

5 Ounsted, C., Lindsay, J., and Norman, R., Biological Factors in Temporal Lobe Epilepsy. Clinics in Developmental Medicine No 22, Spastics Society, and Wm. Heinemann Medical Books Ltd., London, 1966.

- Lennox, M. A., Sibley, W. A., and Zimmerman, H. M., fournal of Pediatrics, 1954, 45, 179.

7 Peterman, M. G., American Fournal of Diseases in Children, 1946, 72, 399. 8 Millichap, J. G., Febrile Convulsions, MacMillan, New York, 1968.

Wallace, S. J., and Zealley, H., Archives of Disease in Childhood, 1970, 45, 611. 10 Sano, K., and Malamud, N., Archives of Neurology and Psychiatry, 1953,
70, 40.

11 Margerison, J. H., and Corsellis, J. A. N., Brain, 1966, 89, 499.

12 Falconer, M. A., Serafetinides, E. A., and Corsellis, J. A. N., Archives of Neurology, 1964, 10, 233.

13 Falconer, M. A., Lancet, 1974, 2, 767

14 Millichap, J. G., Aledort, L. M., and Madsen, J. A., Fournal of Pediatrics, 1960, 56, 364 .

15 Mackintosh, T. F., Clinical Pediatrics (Philadelphia) 1970, 9, 283.

16 Melchior, J. C., 'Buchthal, F., and Lennox-Buchthal, M., Epilepsia (Amsterdam) 1971, 12, 55 .

17 Faero, O., et al., Epilepsia (Amsterdam) 1972, 13, 279.

18 Westmoreland, B., and Bass, N. H., Neurology, 1970, 20, 411 Hutt, S. J., Jackson, P. M., Belsham, A., Higgins, G., Developmental
Medicine and Child Neurology, 1968, 10, 626-632.

20 Wallace, S. J., Archives of Disease in Childhood, 1974, 49, 763.

\section{Suicide in Children}

The myth that children do not become clinically depressed, only miserable, has been firmly squashed by a number of recent observations. ${ }^{1-4}$ The misconception has survived until now because depression in children and young people is often expressed in indirect ways-feelings of boredom, being fed-up, finding nothing worthwhile to do, believing their appearance, their selves, and the world to be all wrong-or it is cloaked by aches and pains, dangerous excitement-seeking, or delinquency.

Children and young people do not only threaten suicide; they may carry out their threats, ${ }^{5}$ as was highlighted by the suicide of a schoolgirl in Southampton. ${ }^{6}$ Shaffer made a careful study $^{7}$ of all suicides occurring under the age of 14 years between 1962 and 1968 in England and Wales, surveying information from school medical and social records, but he did not talk to the families themselves-a humane limit applied by the Registrar General. In all 31 children and young people killed themselves during the period studied, an incidence of 1 child in 800000 of the population, only $0.08 \%$ of all suicides of whatever age. No child under the age of 12 years killed himself. More boys than girls committed suicide, and the boys tended to use highly lethal methods such as shooting and hanging, while girls took overdoses or used gas. Suicide notes indicated intense feelings of anger and a wish to avoid punishment or humiliation for disciplinary problems at school.

The age of onset at 12 years coincides with pubertal changes with their associated adolescent turmoil, ${ }^{8}$ a maturing concept of death, and less supervision giving more opportunity to carry out suicidal acts. What factors should alert the practitioner to think about the possibility of suicide ? Should threats of suicide be taken seriously? Only $40 \%$ of the child suicides had in fact made threats beforehand, while up to $10 \%$ of referrals to child guidance clinics in one series ${ }^{9}$ had made suicidal threats or gestures. However, it is salutory to note that $30 \%$ of Shaffer's deaths were in children attending or waiting to see a child psychiatrist, though very few because of previous suicidal threats.

Suicidal threats should, then, be taken seriously as cries for help, but they are not in fact predictive of suicide itself in children and young people.

Personality profiles found commonly among suicides included solitary children of superior intelligence attending grammar schools, culturally distant from less well-educated parents; often the mothers were mentally ill and the children depressed, in conflict and withdrawn, having stolen or stayed away from school. Another group were impetuous, aggressive, with violent outbursts, suspicious and resentful of criticism and again often in trouble at school. These are familiar clinical patterns and there are additional factors which may give suggestive pointers-disturbed family backgrounds and divorce, and families where parents or siblings provide models by having attempted or succeeded in committing suicide. Access to means and the opportunity are the final factors, and this can include literature describing ways of committing suicide.

These children have met "failure" of emotional support in their environment early in their lives, and as Winnicott stated ${ }^{10}$ "it is the death that happened, but was not experienced, that is sought . . . sending the body to death, which has already happened in the psyche . . . suicide is no answer . . . it is a despair gesture."

1 Frommer, E. A., British Fournal of Psychiatry. Special publication No. 2, p. $117,1968$.

Rie, H. E., Fournal of the American Academy of Child Psychiatry, 1966, 5, 653.

${ }^{3}$ Caplan, M. G., and Douglas, V. I., Fournal of Child Psychology and Psychiatry and Allied Disciplines, 1969, 10,225.

${ }^{4}$ Malmquist, C. P., New England fournal of Medicine, 1971, 284, 887.

5 Mattson, A., Seese, L. R., and Hawkins, J. W., Archives of General

${ }^{6}$ Butter, N. M., The Tina Wilson Enquiry, Southampton Education Committee, 1974.

Schaffer, D., fournal of Child Psychology and Psychiatry and Allied Disciplines, 1974, 15, 275.

${ }^{8}$ Graham, P., and Rutter, M., Proceedings of the Royal Society of Medicinc, $1973,66,1226$.

Lukianowicz, N., Acta psychiatrica et neurologica Scandinavica, 1968, 44, 416.

10 Winnicntt, D. W., International Review of Psychoanalysis, 1974, 1, 103.

\section{Routine Chest Radiographs in Hospital}

The annual increase ${ }^{12}$ in the number of radiological examinations is estimated to be of the order of $10 \%$; and this is only one aspect of the increasing cost of investigative departments. As the numbers of examinations have increased so have their complexity, and the trend is towards the introduction of more completely new methods.

In the last ten years, isotope scanning, ultrasonography, and more recently the E.M.I. scanner have been introduced to hospital practice, and these methods are becoming a matter of routine patient assessment in some centres. An awareness of their increasing cost to hospitals has led not only administrators but doctors themselves to question some aspects of current medical practice. This has occurred at the official level, ${ }^{3}$ at the clinical level, ${ }^{4}$ and by means of reviews of the use of particular investigations. ${ }^{56}$

While unnecessary or inappropriate laboratory investigations may be criticized on the basis of inconvenience to the patient or cost to the N.H.S. the use of $x$-rays carries the added risk of radiation effects. Recently the benefits and risks of mass radiographic surveys, whether for tuberculosis or cancer, have been the subject of comment. ${ }^{78}$ In a prospective study by Sagel et al. ${ }^{9}$ the value of the routine chest radiograph was assessed on the basis of 10000 examinations obtained exclusively because of hospital admission or scheduled surgery. The results are of considerable interest. In the 521 patients under the age of 20 no case was detected in which serious abnormality was shown on the chest film. A serious abnormality was suspected on the chest radiograph in $16.5 \%$ of all 
patients and in $26 \%$ of those over the age of 40 years. Most of these abnormalities were either cardiomegaly or chronic obstructive pulmonary disease. In three-quarters of these cases the patient when originally seen had a clinical condition in which the chest abnormality was a reasonable possibility. New pathological processes detected in the remaining cases were mostly due to chronic obstructive pulmonary disease, interstitial infiltrates or fibrosis, or mass lesions. In only one patient out of 1855 between the ages of 20 and 39 did the lateral film yield information not visible on the frontal view. In this one patient a collapsed lower dorsal vertebra was found.

Sagel et al. conclude that, while occasionally a treatable condition may be discovered on routine chest radiography in an otherwise healthy child or young adult, the yield is so low in this age group that they recommend its elimination as a standing order; and by extrapolation they also argue there is no case for routine chest radiography in the under 20 s either. Certainly the tuberculin skin test is a much more realistic method than chest radiography for screening for tuberculosis.

A lateral projection is, they suggest, a reasonable request whenever chest disease or a fair possibility of it exists, and in screening examinations over the age of 40 years; but it should be omitted in patients under the age of 40 when chest radiography is used as a routine screening procedure.

Recent policy in Britain on chest radiographs as a screening procedure has, in fact, been in line with the conclusions of these authors. Routine antenatal chest radiographs are no longer being performed, but a chest radiograph is being requested in particular circumstances such as in diabetics or recent immigrants. Many hospitals now consider triannual or even less frequent chest radiographs as adequate for their own employees, whereas until recently an annual chest film was obligatory. It would therefore not require too much persuasion for most surgeons and anaesthetists to accept the recommendation that routine chest radiographs should no longer be done in patients under the age of 20 or even 30 years.

These recommendations, though based on North American experience, conform with good clinical practice; and they are reinforced by arguments of both cost effectiveness and reduction in the radiation risk. The chest radiograph will always remain obligatory when there are clinical indications, but routine requests should be based on something more than tradition.

1 Ashley, J. S. A., Pasker, P., and Beresford, J. C., Lancet, 1972, 1, 890.

2 Swinburne, K., and Burch, P. R. J., Health Trends, 1973, 5, 61

3 Godber, Sir George, Proceedings of the Royal Society of Medicine, 1974, 67,1274 .

67, 1274.

4 Calne, R. Y., Lancet, 1974, 2, 1308.
5 Bull, J. W. D., and Zilkha, K. J., British Medical fournal, 1968, 4, 569.
6 Kreel, L., et al., British Medical fournal, 1974, 4, 31.

${ }^{6}$ Kreel, L., et al., British Medical fournal, 1974, 4,

Boucot, K. R., and Weiss, W., Fournal of the American Medical Association, 1973, 224, 1361 .

9 Sagel, S. S., et al., New England fournal of Medicine, 1974, 291, 1001.

\section{Tailored Treatment for Varicose Veins}

Blood ebbs and flows according to posture in the venous circulation of the legs of patients with incompetent veins, though the general direction of flow is towards the heart. In much the same way fashions come and go in the management of varicosities according to surgical stance. After a wave of enthusiasm in the last decade for nonoperative therapy, are we making any real progress towards better understanding of the problem? There are, indeed, some recent signs that it is possible to strike a rational balance between surgery and sclerosant therapy, but there is still little cause for intellectual satisfaction in our way of dealing with this disorder of uncertain cause.

In 1950 Fegan $^{12}$ reintroduced sclerosant compression therapy (practised on the Continent ${ }^{34}$ since the turn of the century) with the two-fold rationale that varicosis was a progressive proximally spreading disorder consequent upon an initial incompetence of calf perforators and that the obliteration of distal sites of incompetence would diminish the abnormally high flow in the superficial system, thus permitting subsequent proximal recovery. ${ }^{2}$ In spite of the striking short term symptomatic and cosmetic success with even the grossest of varices 256 neither premise has been shown to be true. That would not matter if the 10000 or so patients estimated to be treated yearly in Britian by injection compression? could be assured of long term relief. Up to three years after treatment the technique has been found to compare more than favourably with surgery, ${ }^{8-11}$ but results now becoming available on a five to six year basis from carefully controlled trials are less satisfactory. ${ }^{12} 13$ No fewer than $65 \%$ of patients treated non-operatively were classed as failures after six years by comparison with $22 \%$ of those matched individuals managed by surgical means-and those are results from an enthusiastic centre.

Such crude figures, which relate to all varices, are insufficient to permit a useful analysis. Much more important is the renewed interest in classification that has come from the impact of a shift in therapy and the light this has thrown on the optimum treatment for the individual. Trivial superficial varices without manifest deep-to-superficial incompetence respond well to sclerotherapy and, as might have been expected, poorly to surgery (six-year failures $21 \%$ and $55 \%$ respectively), though it could be questioned in these hard times whether any treatment is justified for this group. Injection also controls below-knee incompetence well, including that occurring in the postphlebitic limb (failures nil for injection and $60 \%$ for surgery). By contrast, saphenofemoral and sapheno-popliteal incompetence, though responding dramatically at first to sclerotherapy, have a dismal sixyear failure rate of $91 \%$; treatment of the isolated incompetent sites by surgery leads in the same period to only $16 \%$ lack of success. Finally, if surgery does fail in this group, presumably because there are undetected distal sites of incompetence, then supplementary sclerotherapy is highly effective ( $8 \%$ failure rate at six years).

These results tell us that there is a place for both methods of treatment, sometimes singly and sometimes combined. The surgeon must analyse the clinical situation and adjust to it rather than take the attitude "here is another patient with varicose veins" and proceed with injection or surgery according to habit. In a representative clinic about $60 \%$ of patients will need some form of surgery because of major incompetence at or proximal to the knee; the remainder can obtain lasting relief from injection-compression. It can be rationally argued, though prospective results are not yet available, that when surgery is used sapheno-femoral ligation with limited stripping from groin to knee will deal with the incompetence, obviate the need for subsequent above-knee sclerotherapy (which carries a high morbidity), and leave the calf free of incisions but treatable by sclerotherapy if occasion demands.

All clinics see a residuum of patients for whom the above carefully worked out rules do not apply. Mostly these are 